\title{
Electrochemical Determination of Anesthetic Drug Ropivacaine in Pharmaceutical Formulations by Differential Pulse Cathodic Adsorptive Stripping Voltammetry
}

\author{
MAHADEVA SINGH JAT, VARSHA JAKHAR, \\ K. K. JHANKAL and D. K. SHARMA* \\ Electrochemical Sensor Research Laboratory, \\ Department of Chemistry, University of Rajasthan, Jaipur (Rajasthan)-302004, India \\ sharmadkuor@gmail.com
}

Received 5 April 2018 / Accepted 25 April 2018

\begin{abstract}
Electrochemical behaviour of ropivacaine at glassy carbon electrode was studied by cyclic and differential pulse cathodic adsorptive stripping voltammetry (DPCAdSV) under different experimental conditions. The voltammetric peak current and potential for the reduction of ropivacaine were analyzed at different $\mathrm{pH}$, scan rate and concentration. The voltammograms exhibited irreversible reduction of ropivacaine in B.R. buffer of $\mathrm{pH}$ 9. The proposed method was successfully applied for the determination of the drug which is commercial liquid. The proposed differential pulse cathodic adsorptive stripping voltammetric method shows limit of detection (LOD) and limit of quantification (LOQ) are $7.79 \times 10^{-7} \mathrm{~g} / \mathrm{mL}$ and $4.26 \times 10^{-7} \mathrm{~g} / \mathrm{mL}$ respectively.
\end{abstract}

Keywords: Ropivacaine, Anaesthetic drug, Cathodic adsorptive stripping voltammetry, Glassy carbon electrode.

\section{Introduction}

Ropivacaine (Figure 1), [(2S)- $N$-(2,6-dimethylphenyl)-1-propylpiperidine-2-carboxamide] is a local anaesthetic drug belonging to the amino amide group. The name ropivacaine refers to both the race mate and the marketed $S$-enantiomer. Ropivacaine hydrochloride is commonly marketed by Neon under the trade name ropin. Ropivacaine may cause central nervous system (CNS) stimulation or depression and cardiac depression. These effects are usually dose-related and result from administration of large doses or unintentional intravascular injection of ropivacaine ${ }^{1-3}$. The drug is generally administered to facilitate surgery. A wide variety of drugs are used in modern anesthetic practice. Many of them are rarely used outside of anesthesia, although others are used commonly by all disciplines. Anesthetics are categorized into two classes: general anesthetics, which cause a reversible loss of consciousness and local anesthetics, which cause a reversible loss of sensation for a limited 
region of the body while maintaining consciousness. It is one of the local anesthetic drugs, the pipecoloxylidides which were first synthesized in $1957^{4-8}$. With the commonly used combined inter-scalene block/general anaesthesia approach to anaesthesia/analgesia for shoulder surgery, the relative role of nerve blockade for postoperative analgesia assumes greater importance over the requirement for surgical anaesthesia and so does the duration of effect of the block. Various analytical methods have been reported for the separation and determination of ropivacaine such as spectroscopy capillary electrophoresis, in which the extraction recovery was 40 and $60 \%$. The results showed high correlation coefficients $\left(\mathrm{R}^{2}>0.999\right)$ for all analytes in the calibration range studied. The limit of quantification ${ }^{9}$ was $2 \mathrm{nM}$. In this High-performance liquid chromatography method, internal standard were observed in the resulting chromatograms at low $\mathrm{ng} / \mathrm{mL}$ levels. The limit of quantitation was $2.5 \mathrm{ng} / \mathrm{mL}^{10}$. Mass spectroscopy, in which the online coupling of chiral capillary zone electrophoresis (CZE) with mass spectrometry (MS) is described for the chiral separation of the basic drug ropivacaine using a coupled capillary system with the possibility of voltage switching. With this set-up, the introduction into the MS of the chiral selector heptakis(2,6-di-o-methyl)-fl-cyclodextrin (DM-fl-CD) that has a detrimental effect on MS performance is avoided. In combination with MS detection, this coupled capillary set-up can be regarded as universally applicable for all CZE separations where the use of buffer additives that have negative influence on the MS is necessary ${ }^{11}$. Voltammetric methods for the determination of drugs in vivo and in vitro are highly selective, sensitive and reproducible. Literature reveals that electrochemical determination of ropivacaine has not been reported earlier, therefore, in the present investigations, these methods have been employed.

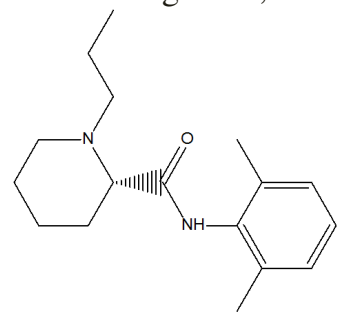

\section{Experimental}

Figure 1. Chemical structure of ropivacaine

Ropivacaine was purchased from local pharmacy under the trade name ropion (Neon) and was used without purification. A stock standard solution of bulk ropivacaine $\left(1 \times 10^{-4} \mathrm{M}\right)$ was prepared in water solvent and preserved at $4{ }^{\circ} \mathrm{C}$ until assessment. A series of BR buffer of $\mathrm{pH}$ values 2 to 12 was prepared and used as a supporting electrolyte. Deionised water was used to prepare all the solutions. The working solutions were prepared by a fix volume of stock solution and buffers. Reagents were used of analytical grade.

\section{Instrumentation}

Employment for electrochemical techniques Model 1230A [SR 400] electrochemical analyzer (CHI Instrument TX, USA), with a totally automated attached to a PC with proper CHI $100 \mathrm{~W}$ version 2.3 software for total control of the experiments, treatment and data collection. A conventional three compartment cell was used for the voltammetric experiments. The working electrode was a $3 \mathrm{~mm}$ diameter glassy carbon electrode (GCE) inserted into a glass tube. The electrode was polished thoroughly with alumina and cleaned in an ultrasonic bath before each measurement. The counter electrode was a platinum wire. The reference electrode is $\mathrm{Ag} / \mathrm{AgCl}$ (1 $\mathrm{M} \mathrm{KCl}$ ). A digital $\mathrm{pH}$-meter (CHINO- DB-1011) fitted with a glass electrode standardized with buffers of known $\mathrm{pH}$ was used for measuring the $\mathrm{pH}$ values of the solutions. 


\section{General procedure}

For total $10 \mathrm{~mL}$ solution, Britton-Robinson of $\mathrm{pH} 9.0$ and the appropriate concentration of the ropivacaine were introduced into the electrochemical cell and purged with pure deoxygenated nitrogen for 10-15 minutes under stirred conditions. These results to remove oxygen gas before measurements. Electrochemical pretreatment was always performed in the same solution in which the measurement was subsequently carried out. The working glassy carbon electrode was polished $0.05 \mu \mathrm{m}$ aluminium oxide and sonicated for a short time to remove impurities on the electrode surface and then it was dried in an oven at $40{ }^{\circ} \mathrm{C}$. After optimization of operational parameters the cyclic and stripping voltammograms were recorded.

\section{Results and Discussion}

Electrochemical studies of ropivacaine were performed using cyclic voltammetry $(\mathrm{CV})$ and differential pulse cathodic adsorptive stripping voltammetry (DPCAdSV). In all electrochemical methods ropivacaine gave one well defined reduction peak at $-1.0 \mathrm{~V} v s$. $\mathrm{Ag} / \mathrm{AgCl}$ reference electrode.

\section{Optimization of $\mathrm{pH}$}

The effect of different supporting buffers (BR carbonate and phosphate) on the current response of ropivacaine was studied in order to assess their impact on the monitored electro analytical signal. The best results with respect to sensitivity accompanied with sharper response were obtained with BR-buffer. Thus study was made in BR-buffer of $\mathrm{pH} 2.0$ to 12 at a targeted concentration of $1 \times 10^{-5} \mathrm{~g} / \mathrm{mL}$ aqueous solution of ropivacaine. Plot of peak potential (Ep) vs. $\mathrm{pH}$ of $1 \times 10^{-4} \mathrm{M}$ solution of ropivacine is shown in Figure $2 \mathrm{~b}$. As depicted in Figure 2a, the peak height attains maxima at $\mathrm{pH} 9.0$ and thereafter decreases. Therefore, pH 9.0 was selected as the optimum $\mathrm{pH}$ for the determination of ropivacaine.
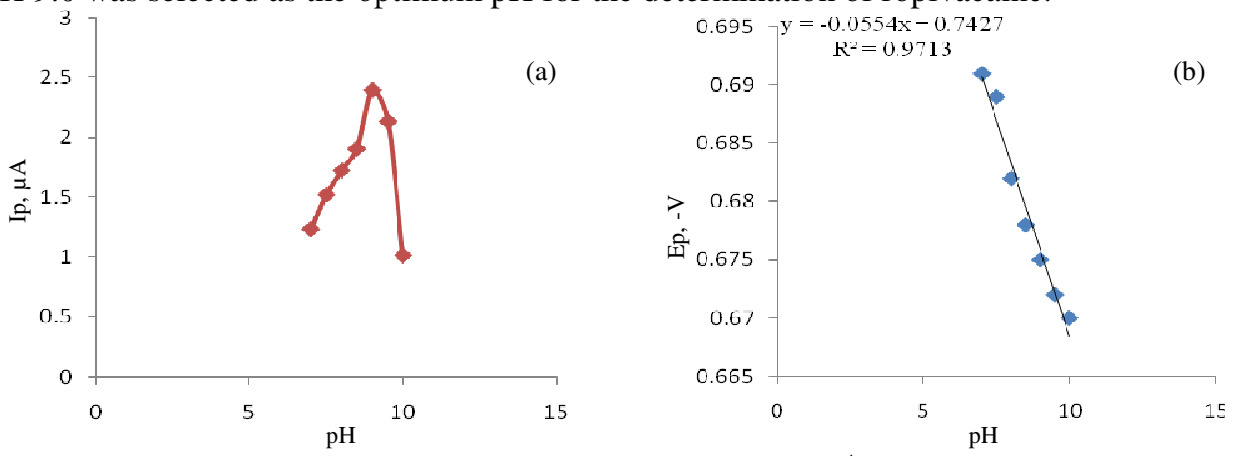

Figure 2. (a) Influence of $\mathrm{pH}$ on DPV peak current of $1 \times 10^{-4} \mathrm{M}$ Ropivacaine in BR Buffer and (b) Plot of peak potential (Ep) vs. $\mathrm{pH}$ of $1 \times 10^{-4} \mathrm{M}$

Furthermore, the peak potential was found to be linearly dependent on $\mathrm{pH}$ indicating about the direct involvement of proton in the reduction process and the corresponding regression equation was found to be $\mathrm{Ep}(\mathrm{V})=-0.0554 \mathrm{pH}+0.7427$ with $\mathrm{r}^{2}=0.9713$.

\section{Cyclic voltammetric behaviour}

Effect of scan rate

The electrochemical behaviour of ropivacaine $\left(1 \times 10^{-4} \mathrm{M}\right)$ in $90: 10(\% \mathrm{v} / \mathrm{v})$ mixtures of Britton-Robinson buffers (BR-buffer) at glassy carbon electrode (GCE) with different $\mathrm{pH}$ was studied by cyclic voltammetry. 
The cyclic voltammogram of ropivacaine in Britton-Robinson buffers exhibits one well-defined reduction peak in the potential range of 0 to $-1.0 \mathrm{~V} v s$. $\mathrm{Ag} / \mathrm{AgCl}$ reference electrode at concentration $1 \times 10^{-4}$ and scan rates 20 to $200 \mathrm{mVs}^{-1}$ (Figure 3). The peak potential shifted towards more negative values with increasing scan rate following the Nicholson theory ${ }^{12}$. There was no peak observed in the anodic direction, suggesting the irreversible nature of the electrode process. This behavior confirmed the irreversible character of electrode reaction. Furthermore, linear plots of peak current $v s$. square root of scan rate following the Ip $\alpha v^{1 / 2}$ should be obtained for a diffusion controlled process, whereas species adsorbed on the electrode surface should result in linear plots of Ip $v s . v$. A linear plot between peak current (Ip) and square root of scan rate $\left(v^{1 / 2}\right)$ indicate about diffusive nature of electrode process consistent with the Randles-Sevcik equation, which can be expressed as Ip $=\left(2.99 \times 10^{5}\right) n\left[\alpha^{\prime}\right]^{1 / 2} \mathrm{~A} \mathrm{C}_{\mathrm{o}} \mathrm{D}_{\mathrm{o}}{ }^{1 / 2} v^{1 / 2}$, where $\mathrm{n}$ is the number of electrons exchanged in reduction, $\mathrm{n}$ ' is the number of electrons involved in the rate determining step, $\alpha$ is the charge transfer coefficient, $\mathrm{A}\left(\mathrm{cm}^{2}\right)$ is the apparent surface area of the electrode, $\mathrm{C}_{0}(\mathrm{~mol} / \mathrm{L})$ is the concentration of the electroactive species, $\operatorname{Ip}(\mu \mathrm{A})$ is the cathodic peak current, $D_{0}\left(\mathrm{~cm}^{2} \mathrm{~s}^{-1}\right)$ is the diffusion coefficient of the electroactive species and $v\left(\mathrm{mV} \mathrm{s}^{-1}\right)$ is the scan rate.

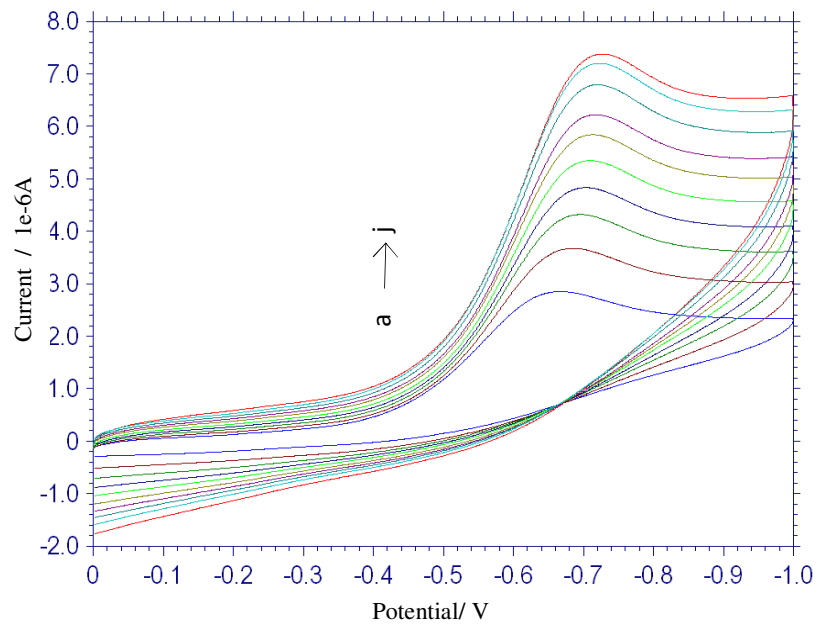

Figure 3. Cyclic voltammogram of $1 \times 10^{-4} \mathrm{M}$ Ropivacaine in BR-buffer at different scan rates: (a) $20 \mathrm{mV} / \mathrm{s}$ (b) $40 \mathrm{mV} / \mathrm{s}$ (c) $60 \mathrm{mV} / \mathrm{s} \mathrm{(d)} 80 \mathrm{mV} / \mathrm{s} \mathrm{(e)} 100 \mathrm{mV} / \mathrm{s}$ (f) $120 \mathrm{mV} / \mathrm{s} \mathrm{(g)} 140$ $\mathrm{mV}^{-1}$ (h) $160 \mathrm{mV} / \mathrm{s}$ (i) $180 \mathrm{mV} / \mathrm{s}$ (j) $200 \mathrm{mV} / \mathrm{s}$ at $\mathrm{pH} 9.0$

$$
\mathrm{Ip}(\mu \mathrm{A})=0.192 v^{1 / 2}(\mathrm{mV} / \mathrm{s})^{1 / 2}+0.288(\mu \mathrm{A}), \mathrm{R}^{2}=0.981
$$

The linear relationship existing between peak current (Ip) and square root of the scan rate $\left(v^{1 / 2}\right)$ with a slope 0.192 confirms the diffusive nature of reduction of ropivacaine (Figure 4).

The linear regression equation related to the plot of logarithm of peak current $\mathrm{Ip}(\mu \mathrm{A})$ $v s$. logarithm of scan rate $(\mathrm{mV} / \mathrm{s})$ was found to be $\log (\mathrm{Ip})=0.4103 \log v-0.4763$ with $\mathrm{r}^{2}=$ 0.995. Figure 5 shows a plot between $\log \mathrm{Ip} v / \mathrm{s} \log v$. Slope of this curve $(0.491 \log \mathrm{Ip} / \log \mathrm{v})$ is very close to the theoretical value of 0.5 for a pure diffusion controlled process ${ }^{13-17}$. Moreover, intercept in the plot may be attributed to some adsorption interference present in the electrode process; due to this the rate determining step of the reduction process was termed to be partially diffusion controlled. 


\section{Differential pulse voltammetric studies}

The best result with respect to signal evaluation and peak shape accompanied by sharper response was obtained ${ }^{22,23}$ with $\mathrm{BR}$ buffer at $\mathrm{pH}$ 9. This supporting electrolyte was chosen for the subsequent experiments. In order to develop a voltammetric method for the trace element study of the ropivacaine in pharmaceuticals differential pulse voltammetry (DPV) was developed. DPV is effective and quick electroanalytical technique with well-established advantages, including good discrimination against background current, high sensitivity, substantial speed and low detection limits ${ }^{24}$.

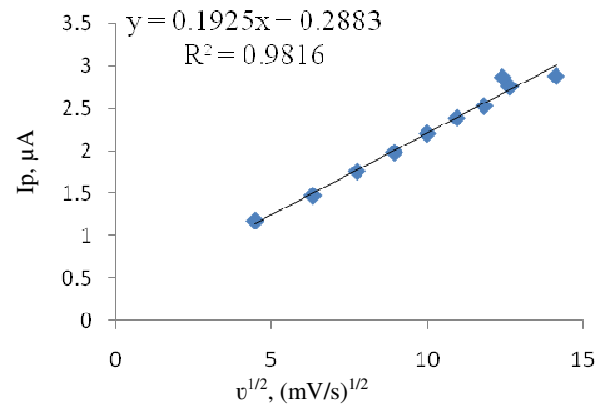

Figure 4. Plot of Ip vs. $v^{1 / 2}$ for the cyclic voltammogram of $1 \times 10^{-4} \mathrm{~mol} \mathrm{~L}^{-1}$ ropivacaine Britton-Robinson buffer of $\mathrm{pH} 9.0$

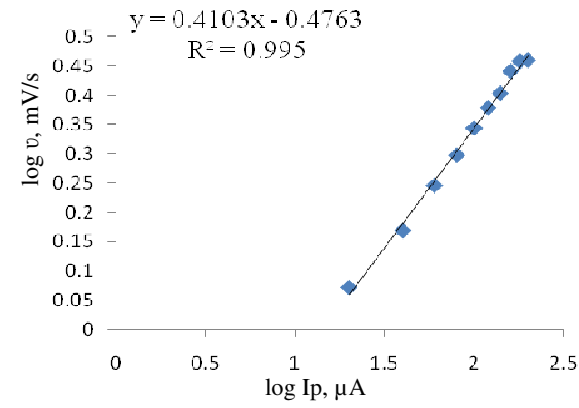

Figure 5. Influence of scan rate $\left[\log v\left(\mathrm{mVs}^{-1}\right)\right]$ on peak potential $(\mathrm{Ep} / \mathrm{V})$ of cyclic

voltammograms of ropivacaine

\section{Validation of the procedure}

Validation of the proposed DPV technique for the analysis of ropivacaine in pharmaceutical dosages forms was carried out via estimation of the range of linearity, the limit of detection (LOD) and the limit of quantification (LOQ $)^{25,26}$. The applicability of the proposed DPV procedure as analytical methods for the determination of ropivacaine was examined by measuring the peak current of stripping mode. The Differential Pulse Voltammetry (DPV) of ropivacaine at concentration over the $0.2 \times 10^{-6} \mathrm{M}$ to $1.2 \times 10^{-5} \mathrm{M}$ is shown in Figure 6 . The linear regression equation is expressed as

$$
\mathrm{Ip}(\mu \mathrm{A})=1.254 \mathrm{C}\left(10^{-4} \mathrm{M}\right)+4.278\left(10^{-4} \mathrm{~A}\right), \mathrm{R}^{2}=0.9822
$$

The regression plot showed that there is a linear dependence of the current intensity on concentration in DPV technique over the $0.2 \times 10^{-6} \mathrm{M}$ to $1.2 \times 10^{-5} \mathrm{M}$ is shown in Figure 7 .

\section{Limit of detection}

The limit of detection (LOD) is an important quantity in chemical analysis. The LOD is the smallest concentration or amount that can be detected with reasonable certainty for a given analytical procedure. The detection limit was calculated by the equation ${ }^{27}$.

$$
\mathrm{LOD}=3 \mathrm{SD} / b
$$

Where SD is the standard deviation of the peak currents (five runs) and $b$ is the slope of the calibration curve. The calculated detection limit of the standard solution for DPCAdsV and DPV was $1.28 \times 10^{-7} \mathrm{~g} / \mathrm{L}$. Peak is not resolved from the noise at concentration lower than LOD.

\section{Quantification limit}

The limit of quantification (LOQ) is the lower limit of concentration for precise quantitative measurements ${ }^{28,29}$. The quantification limit was examined by the equation

$$
\mathrm{LOQ}=10 \mathrm{SD} / b
$$


The limit of quantification for the standard solution was found to be $4.26 \times 10^{-7} \mathrm{~g} / \mathrm{L}$ for DPCAdsV with $0.78 \%$ relative standard deviation and $2.49 \times 10^{-7} \mathrm{~g} / \mathrm{ML}$ for DPV with relative standard deviation of $0.62 \%$. Therefore DPCAdSV is more sensitive than DPV ${ }^{30}$.

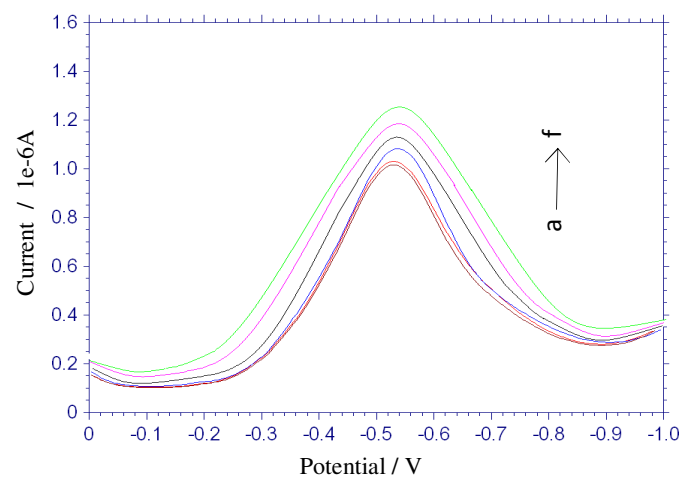

Figure 6. The DP-voltammograms of ropivacaine at different concentrations (a) $0.2 \times 10^{-5} \mathrm{M}$, (b) $0.4 \times 10^{-5} \mathrm{M}$, (c) $0.6 \times 10^{-5} \mathrm{M}$, (d) $0.8 \times 10^{-5} \mathrm{M}$, (e) $1 \times 10^{-5} \mathrm{M}$ and (f) $1.2 \times 10^{-4} \mathrm{M}$ in pharmaceutical form in BR buffer $(\mathrm{pH}=9.0)$ at glassy carbon electrode

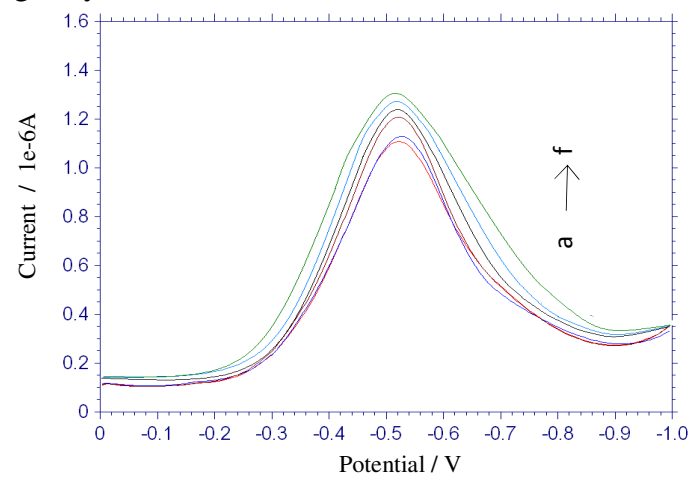

Figure 8. The DP-CadS voltammograms of ropivacaine at different concentrations (a) $0.2 \times 10^{-7}$ $\mathrm{M}$, (b) $0.4 \times 10^{-7} \mathrm{M}$, (c) $0.6 \times 10^{-7} \mathrm{M}$, (d) $0.8 \times 10^{-7} \mathrm{M}$, (e) $1 \times 10^{-6} \mathrm{M}$ and (f) $1.2 \times 10^{-6} \mathrm{M}$ in pharmaceutical form in BR buffer ( $\mathrm{pH} 9.0)$ at glassy carbon electrode

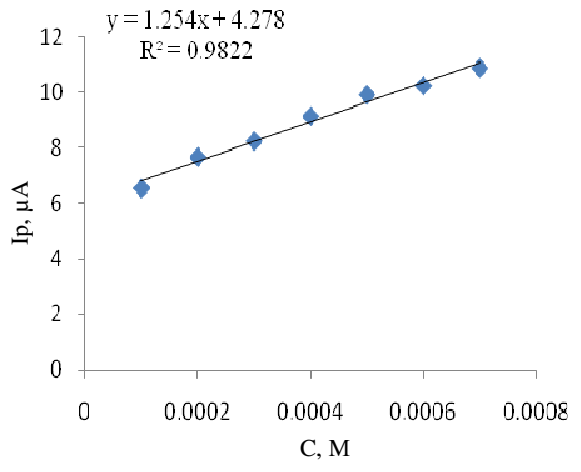

Figure 7. Plot of peak current (Ip) vs. concentrations (C) for ropivacine at scan rate $100 \mathrm{mV} / \mathrm{s}$ in BR-buffer of $\mathrm{pH} 9.0$

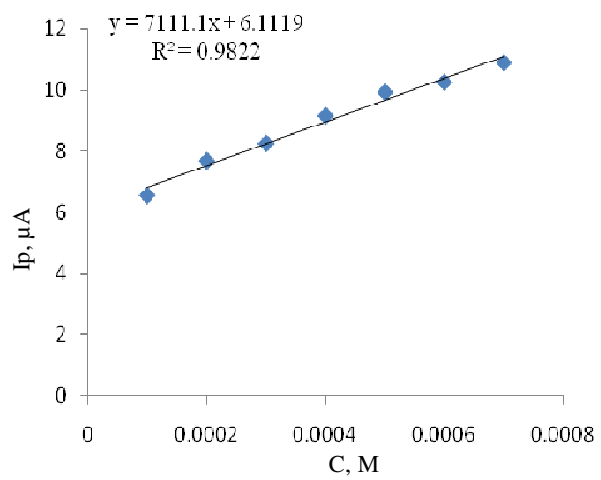

Figure 9. Plot of peak current (Ip) vs. concentrations (c) for Ropivacine at scan rate $100 \mathrm{mV} / \mathrm{s}$ in BR-buffer of $\mathrm{pH} 9.0$

\section{Differential pulse cathodic adsorptive stripping voltammetric studies}

The differential pulse cathodic adsorptive stripping voltammograms are shown in Figure 8 over the concentration range $1 \times 10^{-7}$ to $2.2 \times 10^{-6} \mathrm{M}$. The linear regression equation is expressed as

$$
\operatorname{Ip}(\mu \mathrm{A})=2.199 \mathrm{C}\left(10^{-4} \mathrm{M}\right)+6.9911\left(10^{-4} \mathrm{~A}\right) \quad \mathrm{R}^{2}=0.992
$$

The regression plot (Figure 9) showed that there is a linear dependence of the current intensity on concentration ${ }^{31}$. The calculated detection limit for the standard solution was $7.79 \times 10^{-7} \mathrm{M}$. The limit of quantification was found to be $2.59 \times 10^{-6} \mathrm{M}$ (Table 1). 
Table 1. Characterisation data of ropivacaine calibration plots in BR buffer of $\mathrm{pH}$ value 9.0 for DPV and DPCAdSV methods

\begin{tabular}{ccc}
\hline Parameters & DPCAdSV & DPV \\
\hline Linearity range $(\mathrm{M})$ & $0.2 \times 10^{-7}$ to $2.2 \times 10^{-6}$ & $0.2 \times 10^{-5}$ to $1.2 \times 10^{-5}$ \\
Slope $(\mathrm{A} / \mathrm{M})$ & 2.1994 & 1.254 \\
Intercept $\left(10^{-4} \mathrm{~A}\right)$ & 6.9911 & 4.278 \\
LOD $(\mathrm{M})$ & $7.79 \times 10^{-7} \mathrm{M}$ & $1.28 \times 10^{-6} \mathrm{M}$ \\
LOQ $(\mathrm{M})$ & $4.26 \times 10^{-7} \mathrm{M}$ & $2.59 \times 10^{-6} \mathrm{M}$ \\
Standard Deviation & $0.78 \%$ & $0.62 \%$ \\
Correlation Coefficient $\left(\mathrm{R}^{2}\right)$ & 0.992 & 0.9822 \\
\hline
\end{tabular}

\section{Conclusion}

We were able to examine the voltammetric behaviour of ropivacaine in aqueous media. The electrochemical reduction of ropivacaine under the conditions described in this work is irreversible process controlled by diffusion. A validated differential pulse and square wave stripping voltammetric procedure was developed and successfully applied to the estimation of ropivacaine in pharmaceutical formulation. These methods are quick and relatively cheap to operate compared with alternative HPCL methods. They are suitable for routine analysis in quality control laboratories, to be applied for the analysis of ropivacaine in pure form and in pharmaceutical formulation. In these methods, the high percentage of recovery shows that the compound are almost completely extracted from tablet formulation and the result indicate that the developed method can be used to quantify ropivacaine without interference from other in gradients.

\section{Acknowledgment}

One of the authors (MSJ) is thankful to Council of Scientific and Industrial Research, New Delhi for providing financial assistance as JRF.

\section{References}

1. Alahuhta S, Räsänen J, Jouppila P, Kangas-Saarela T, Jouppila R, Westerling P and Hollmen A I, Anesthesiology, 1995, 83(1), 23-32; DOI:10.1097/00000542199507000-00004

2. Datta S, Camann W, Bader A and Laura Vander Burgh R N, Anesthesiology, 1995, 82, 1346-1352.

3. Griffin R and Reynolds F, Brit J Anaesth., 1995, 74(5), 512-516;

DOI:10.1093/bja/74.5.512

4. Eddleston J M, Holland J J, Griffin R P, Corbett A, Horsman E L and Reynolds F, Brit J Anaesth., 1996, 76(1), 66-71; DOI:10.1093/bja/76.1.66

5. McCrae A F, Jozwiak H and McClure J H, Brit J Anaesth., 1995, 74(3), 261-265; DOI:10.1093/bja/74.3.261

6. Stienstra R, Jonker T, Bourdrez P, Kuijpers J C, van Kleef J W and Lundberg U, Anesth Analg., 1995, 80(2), 285-289.

7. Brockway M S, Bannister J, McClure J H, Mckeown D and Wildsmith J A W, Brit J Anaesth., 1991, 66(1), 31-37; DOI:10.1093/bja/66.1.31

8. Hickey R, Hoffman J and Ramamurthy S, Anesthesiology, 1991, 74, 639-642.

9. Abdel-Rehim M, Altun A and Blomberg L, J Mass Spectro., 2004, 39(12), 14881493; DOI:10.1002/jms.731 
10. Stumpe M, Morton N S and Watson D G, J Chromatogr B: Biomed Sci Appl., 2000, 748(2), 321-330; DOI:10.1016/S0378-4347(00)00346-7

11. Lamoree M H, Sprang A F H, Tjaden U R and van der Greef J, J Chromatogr A, 1996, 742(1-2), 235-242; DOI:10.1016/0021-9673(96)00225-7

12. Nicholson R S, Anal Chem., 1965 37(11), 1351-1355; DOI:10.1021/ac60230a016

13. Bard A J and Faulkner L R, Electrochemical Methods: Fundamentals and Applications, John Wiley and Sons. Inc., New York, 2001.

14. Armbruster D A, Tillman M D and Hubbs L M, Clin Chem., 1994, 40(7), 1233-1238.

15. Hay I D, Bayer M F, Kaplan M M, Klee G G, Larsen P R and Spencer C A, Clin Chem., 1991, 37(11), 2002-2008.

16. Kissinger $\mathrm{P} \mathrm{T}$ and Heinman $\mathrm{W}$ R, Laboratory Techniques in Electroanalytical Chemistry, Wang J, Electro Analytical Chemistry, Wiley-VCH Publication, New York, 2006, 167.

17. Uslu B, Ozkan S A and Sentürk Z, Anal Chim Acta, 2006, 555(2), 341-347; DOI:10.1016/j.aca.2005.09.034

18. Tasdemir I H, Akay M A, Erk N and Kilic E, Electroanalysis, 2010, 22(17-18), 21012109; DOI:10.1002/elan.201000100

19. Bond A M, Broadening Electrochemical Horizons: Principal and Illustration of Voltammetric and Related Techniques, Oxford Universitry Press: New York, 2002.

20. Fang H,Zhou J Zhou S, Dai W, Li C, Du D and Shen X, Sensors Actuators B, 2015, 210, 113-119; DOI:10.1016/j.snb.2014.12.093

21. Liu S C, Wei Y Z, Liu R Q and Fang B Z, Sci China Chem., 2013, 56(12), 17431748; DOI:10.1007/s11426-013-4945-2

22. Diculescu V C, Vivan M and Bretta A M O, Electroanalysis, 2006, 18(18), 18001807; DOI:10.1002/elan.200603591

23. Jain R and Sharma S, J Pharm Anal., 2012, 2(1), 56-61;

DOI:10.1016/j.jpha.2011.09.013

24. Kumari $\mathrm{M}$ and Sharma D K, J Korean Chem Soc., 2011, 55, 50; DOI:10.5012/jkcs.2011.55.1.050

25. Mourya G L, Jhankal K K, Parashar P and Sharma D K, Der Pharm Sinica., 2012, 3(6), 708-714.

26. Clinical and Laboratory Standards Institute. Protocols for Determination of Limits of Detection and Limits of Quantitation, Approved Guideline. Wayne, PA USA: CLSI; CLSI document EP17, 2004.

27. Needleman S B and Romberg R W, J Anal Toxicol., 1990, 14(1), 34-38; DOI:10.1093/jat/14.1.34

28. Lawson G M, Clin Chem., 1994, 40(7), 1218-1219.

29. Brett C M A and Brett A M O; Electrochemistry-Principles, Methods and Applications, Oxford University Press, Oxford, 1993, ISBN 0-19-855388-9; DOI: 10.1002/bbpc.19940981033

30. Sharma D K, Mourya G L, Jhankal K K, Jones L A and Bhargava S K, Der Pharm Lett., 2012, 4(5), 1599-1606.

31. Jhankal K K, Sharma A, Ramswaroop and Sharma D K, J Pharma Sci Res., 2015, 7(1), 10-16.

32. Sinha P, Shekhawat A and Sharma D K, Rep Electrochem., 2015, 5, 21-28; DOI:10.2147/RIE.S90750 